\title{
Construction Monitoring and Control of PC Composite Box-girder with Corrugated Steel Webs
}

\author{
Xiaoyong Chen 1, a, Yingbo Zhu ${ }^{2, b}$, Yunfei $\mathrm{Xia}^{3, \mathrm{c}}$ and Shui Wan ${ }^{4, \mathrm{~d}}$ \\ ${ }^{1}$ Huzhou Traffic Engineering Construction Group Co., Ltd., Huzhou, China \\ ${ }^{2}$ School of Transportation, Southeast University, Nanjing, China \\ ${ }^{3}$ Huzhou Traffic Engineering Construction Group Co., Ltd., Huzhou, China \\ ${ }^{4}$ School of Transportation, Southeast University, Nanjing, China \\ a85426135@qq.com, byingbozhu@126.com, ‘492314565@qq.com, dlanyu421@163.com
}

Keywords: Monitoring; Control; Corrugated Steel Webs; Principle; Adaptive control; Analysis Abstract. The purpose of bridge construction monitoring and control is to ensure control indicators within allowable range by measuring and correcting, and to ensure the safety and quality of the bridge during the construction stage. Based on a prestressed concrete composite box-girder with corrugated steel webs, this paper introduces the principles and methods of construction monitoring and control, uses Midas/ Civil to carry out finite element simulation of the bridge, adopts an adaptive control method to analyze and corrects the measured and theoretical values of monitoring. The results show that the bridge is under a safe and reasonable stress state in construction stages, and the actual alignment of the bridge is in good agreement with the ideal alignment.

\section{Introduction}

The prestressed concrete composite box-girder with corrugated steel webs is a new kind of composite girder bridge with box girder webs replaced by corrugated steel webs. The PC composite box-girder with corrugated steel webs has the advantages of light weight, large span capacity, strong earthquake resistance, excellent shear strength that avoid cracks, high prestressing efficiency, improving the efficiency of steel, and has a wide application prospect $[1,2]$.

The purpose of bridge construction monitoring and control is to ensure the safety and quality of the bridge during construction, to make sure the stress, the axis and the deflection of the bridge are within allowable range under the specified load, to ensure deviations can be timely found and corrected during construction stages, and to achieve the ideal alignment and structure stress state [3]. Currently, few PC composite box-girders with corrugated steel webs are built or under construction in the world. And for long-span corrugated steel webs girder bridges, there is little construction technology in cantilever construction. Therefore, it is necessary to carry out detailed monitoring and control of the cantilever construction for long-span PC composite box-girder with corrugated steel webs. Based on Yingjie bridge- PC composite box-girder with corrugated steel webs, this paper designed and carried out construction monitoring and control, and the result of construction monitoring is satisfying.

\section{General Situation of Yingjie Bridge}

Yingjie Bridge is located in Huzhou, Zhejiang Province, which is a three-span PC composite box-girder with corrugated steel webs with variable cross section. Cantilever construction method was used in Yingjie Bridge, including 10 cantilever casting segments, and the side span is closed firstly and then the middle. The main span is $(52+90+52) \mathrm{m}$ and the cross section is single-box single-cell box-girder. The fulcrum beam is $5.8 \mathrm{~m}$ high and the middle beam is $2.8 \mathrm{~m}$ high. The standard section of Yingjie Bridge is $2.75 \mathrm{~m}$ (pavement and railing) $+2.5 \mathrm{~m}$ (non-motor lanes) + $2 * 3.5 \mathrm{~m}$ (motor lanes) $+0.5 \mathrm{~m}$ (side trip) $+0.75 \mathrm{~m}$ (railing) +0.5 (medial divider) $+0.75 \mathrm{~m}$ (railing) $+0.5 \mathrm{~m}$ (side trip) $+2 * 3.5 \mathrm{~m}$ (motor lanes) $+2.5 \mathrm{~m}$ (non-motor lanes ) $+2.75 \mathrm{~m}$ (pavement and railing). Corrugated steel webs used in Yingjie bridge is 1600 type, with $1.6 \mathrm{~m}$ wavelength, $0.22 \mathrm{~m}$ wave height 
and $0.43 \mathrm{~m}$ horizontal panel width, and four different thickness types-10mm, $14 \mathrm{~mm}, 16 \mathrm{~mm}$ and $18 \mathrm{~mm}$. A combination of internal prestressing and external prestressing was used to ensure safety of Yingjie Bridge.

\section{Finite Element Analysis}

This paper used MIDAS /Civil to carry out finite element simulation of the structure. The main beam structure is established, and is divided into 58 elements. The finite element model and the standard cross section are showed in Fig. 1 and 2.

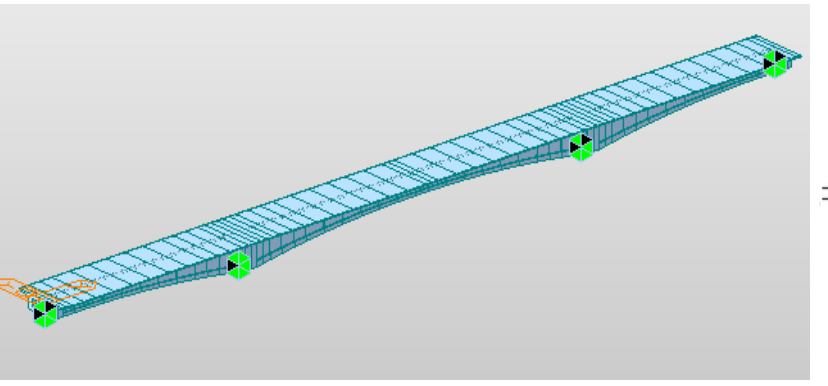

Fig. 1. Finite element simulation of Yingjie bridge

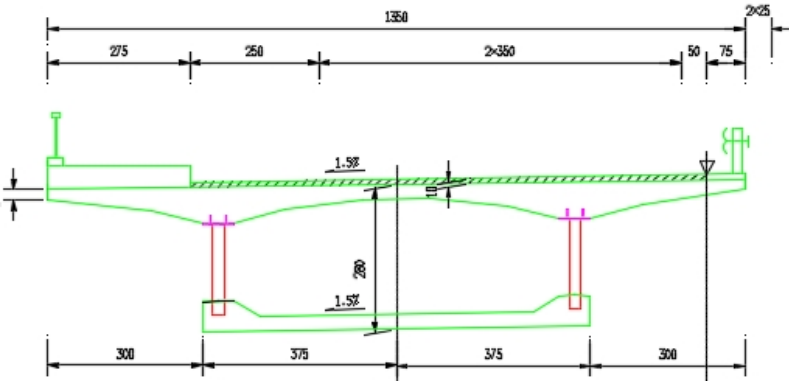

Fig. 2. Standard cross section of Yingjie bridge(unit: $\mathrm{cm}$ ) C50 concrete was used in the main girder of Yingjie bridge, whose dead weight of C50 concrete is about $2.60 \mathrm{~kg} / \mathrm{m}^{3}$ and elastic modulus is $3.45 \times 10^{4} \mathrm{MPa}$. The shrinkage and creep properties of the concrete material should be determined in accordance with Chinese code. The yield strength of corrugated steel webs was $335 \mathrm{MPa}$, whose dead weight is $7.85 \mathrm{~kg} / \mathrm{m}^{3}$ and elastic modulus is $2.06 \times 10^{5} \mathrm{MPa}$. Low-relaxation and high-quality steel strands are used in the main girder, whose elastic modulus is $1.95 \times 10^{5} \mathrm{MPa}$, and the tensile strength is over $1860 \mathrm{MPa}$. The tensile stress of the internal steel strands is $1395 \mathrm{MPa}$ and the external tensile stress is $1116 \mathrm{MPa}$.

The bending stress caused by various loads shall be calculated during each construction stage, which should be lower than allowable stress. Due to the accordion effect of corrugated steel webs in PC composite box-girder with corrugated steel webs, the corrugated steel webs can not resist axial forces and bending moments. So only the action from the concrete roof and floor should be considered, and assume that the plane-section behavior is true [4]. Thus, the stress of roof and floor can be calculated easily.

Stress envelope diagram in construction stages can be extracted from the finite element model, as shown in Fig. 3 and 4.

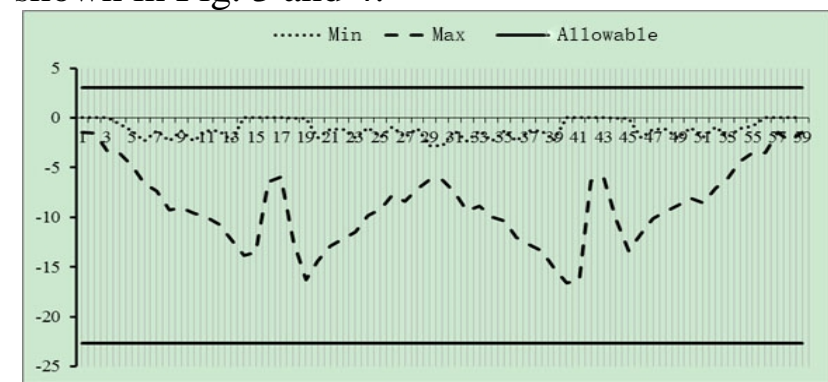

Fig. 3. Stress envelope diagram of roof (unit: MPa)

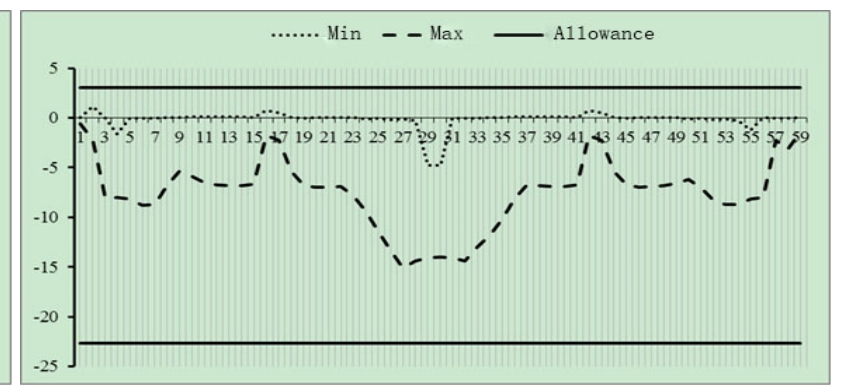

Fig. 4. Stress envelope diagram of floor (unit: MPa)

In accordance with Chinese code, the deflection of the flexural members at the service stage should take into account the long-term effects of the load. Under the effect of short-term loading, the long-term deflection of Yingjie bridge is $54.8 \mathrm{~mm}$, without long-term deflection caused by the weight of the structure, which is less than the limit value $L / 600=150 \mathrm{~mm}$, satisfying the requirement.

\section{Bridge Construction Monitoring and Control Programme}

Principles of Monitoring and Control. Bridge construction monitoring and control is a cyclic process of construction, measurement, identification, correction and construction. The most important part in construction monitoring is the control of internal forces, alignment and stability. The 
main control indicators are the stress of the upper and lower edges of section and the elevation of the main girder, which makes the section stress to meet the requirements of design and specification during bridge construction stages, and makes the actual alignment to conform to the ideal alignment as much as possible [5].

Methods of Monitoring and Control. The design parameters such as cross-section dimensions, installation of corrugated steel webs, tensile forces of prestressing tendons, elastic modulus of materials, dead weight, shrinkage coefficient, and creep coefficient are often different from the actual conditions in construction. This leads to that the deformation of bridge under each construction condition can't reach the ideal design status. In addition, factors such as temperature, temporary loads, and construction errors can also deviate the actual deformation of the structure from the ideal state of the design.

Yingjie Bridge mainly adopts an adaptive control method, that is, when the construction error is generated, passive adjustment measures will be used to reduce the influence of the structural state error that has been generated on the final structural state $[6,7]$. The specific approach is to collect data such as elevation, strain, temperature, section size, and elastic modulus of the main beam during construction, and analyse error of the measured data, then rationally correct calculation parameters in the finite element model and the construction parameters, so that the difference between the design value of the elevation and stress and the actual measured value will narrow gradually. In this way, the next construction status can be predicted through the analysis of the current construction situation, which achieves the purpose of construction control.

Layout of Monitoring Point. Displacement monitoring includes displacement of the main girder (including positioning of corrugated steel webs) and settlement of main piers. Generally, geometrical leveling methods are used to measure the absolute elevation of the leveling point for each segment that has been constructed, and then calculate the beam bottom elevation for the corresponding segment.

In each stage of construction, the elevation of each section of Yingjie Bridge shall be measured. There shall be 3 measurement points for each section, a total number of 282 displacement monitoring points for double amplitude, as shown in Fig. 5.

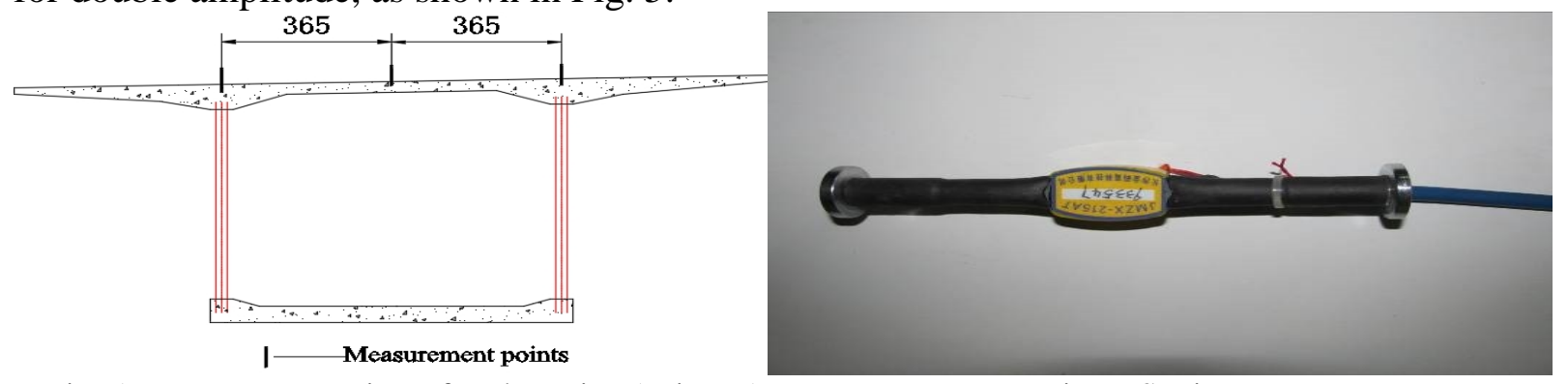

Fig. 5. Measurement points of each section (unit: $\mathrm{cm}$ )

Fig. 6. Strain gauge

Stress monitoring includes the normal stress at the upper and lower edges of the most unfavorable cross section and the construction control of corrugated steel webs under the maximum cantilever construction stage. During the cantilever construction of continuous girder bridge, the root of 1\# segment is the cross section with the largest moment. The concrete normal stress at the upper and lower edges of the section should be kept within the permissible range at construction each stage so that the construction can be carried out safely and smoothly.

Considering that the strain gauge should be suitable for observation in long-term construction and can ensure sufficient accuracy, a vibrating-string concrete strain gauge with long-term, good stability, and high precision will be used for normal stress testing, as shown in Fig. 6.

According to the construction sequence, the right bridge is used as the key monitoring area and the left bridge is used as the control group. Given consideration to the stress characteristics of cantilever construction of PC composite box-girder with corrugated steel webs and the main purpose of construction control, 11 strain test sections for the key monitoring area are chosen: root, 1/4 span, mid-span, and 3/4 span in main span; root, 1/4 span, mid span in the side span. Six strain gauge points 
are arranged for each section, totally 66 measurement points in the key monitoring area. The layout of the key monitoring area is shown in Fig. 7 and 8. There are five strain test sections in the control group: a total of 30 measurement points in A1-A1 section, B1-B1 section, D-D section, E1-E1 section, E2-E2 section as shown in Fig. 7. Take the average value of the three measuring points on the top or the bottom plates as the concrete normal strain.

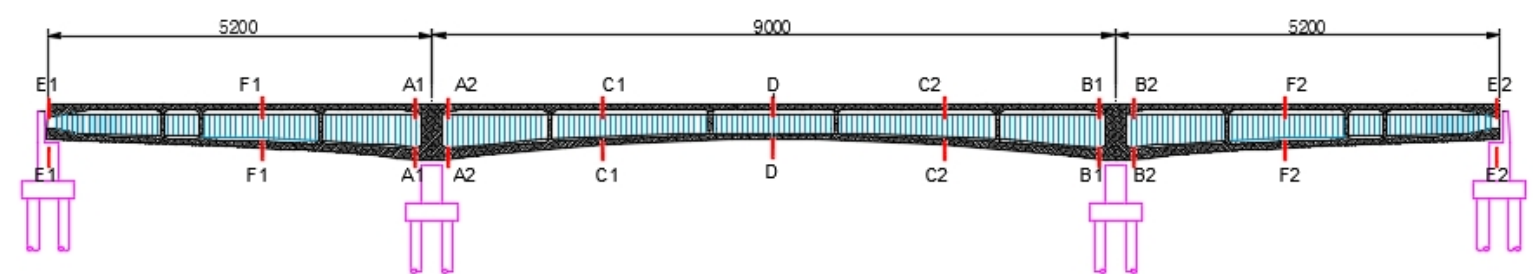

Fig. 7. Test sections for the key monitoring area (unit: $\mathrm{cm}$ )

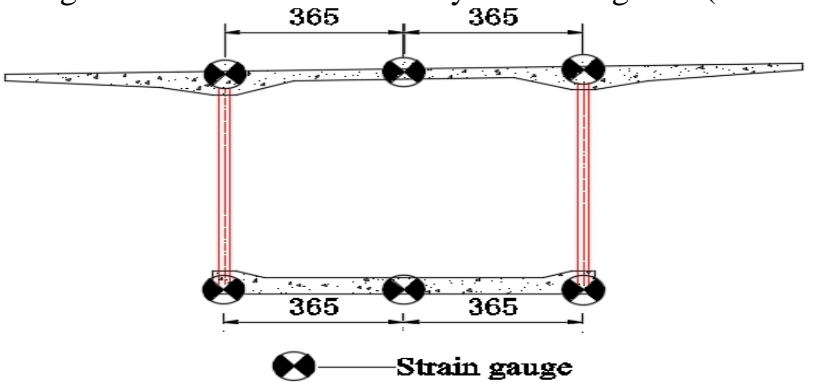

Fig. 8. Layout of Strain gauge for each test section (unit: $\mathrm{cm}$ )

\section{Analysis of Measured Data}

In each construction stage, the bridge alignment was monitored carefully and adaptive control method is applied to adjust the parameters in the next stage. When Closure, the comparison between the measured values of left bridge and right bridge and the theoretical values is shown respectively in Fig. 9 and 10. Graph shows that the measured values are in agreement with the theoretical values by monitoring and controlling, and the maximum error is $2 \mathrm{~cm}$, satisfying the construction tolerances. The alignment of Yingjie Bridge is very beautiful, as shown in Fig.11.

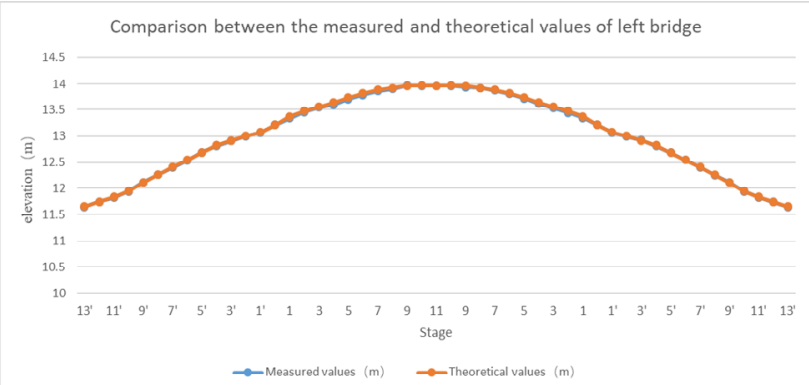

Fig. 9. Comparison between the measured and theoretical alignment values of left bridge (unit: $\mathrm{m}$ )

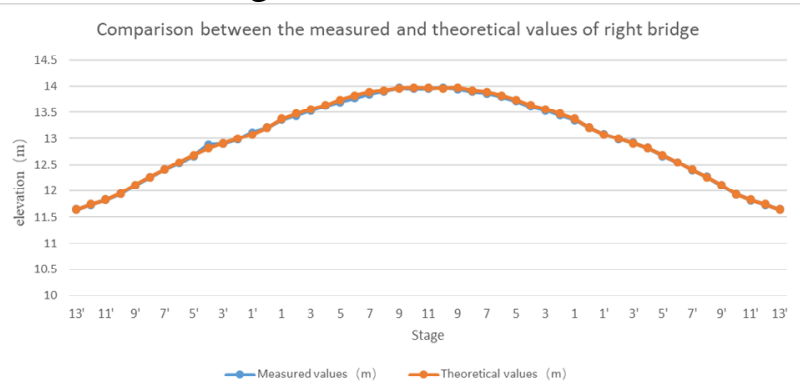

Fig. 10. Comparison between the measured and theoretical alignment values of right bridge (unit: $\mathrm{m}$ )

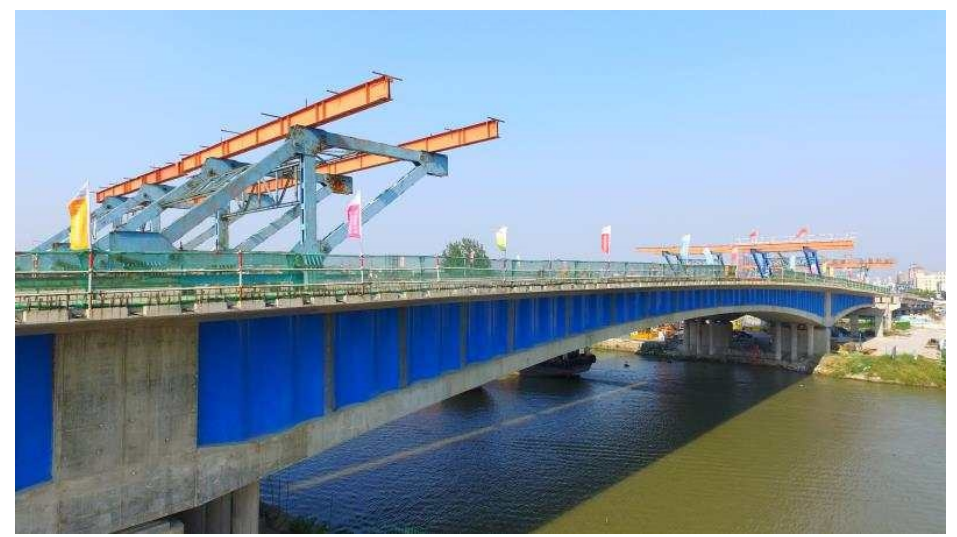

Fig. 11. The alignment of Yingjie Bridge 
The normal stress at the upper and lower edges of $\mathrm{C}-\mathrm{C}$ section are shown in Table 1 and 2 . It can be seen from the graph that $\mathrm{C}-\mathrm{C}$ section is under pressure during the entire construction stages and the development trend of measured compression stress is basically consistent with the theoretical compression stress. What is more, the measured compression stress is higher than the theoretical. That is to say, the measured normal stress is relatively safer. Yingjie Bridge under construction is in a reasonable and safe stress and smoothly closed.

Table 1 The normal stress at the upper edges of $\mathrm{C}-\mathrm{C}$ section(unit: $\mathrm{MPa}$ )
Table 2 The normal stress at the lower edges of $\mathrm{C}-\mathrm{C}$ section(unit: $\mathrm{MPa}$ )

\begin{tabular}{cc|c|c}
\hline & & $\begin{array}{l}\text { Measured } \\
\text { value }(\mathrm{MPa})\end{array}$ & $\begin{array}{l}\text { Theoretical } \\
\text { value }(\mathrm{MPa})\end{array}$ \\
\hline 4\# & segment stage & -1.034 & 0.0946 \\
\hline $5 \#$ & segment stage & -1.593 & -0.221 \\
\hline $6 \#$ & segment stage & -2.189 & -0.994 \\
\hline $7 \#$ & segment stage & -3.418 & -1.95 \\
\hline $8 \#$ & segment stage & -5.279 & -3.26 \\
\hline 9\# $\quad$ segment stage & -3.109 & -4.74 \\
\hline 10\# $\quad$ segment stage & -7.84 & -6.57 \\
\hline \multicolumn{2}{c|}{ side span closure } & -6.841 & -5.29 \\
\hline middle span closure & -6.784 & -4.79 \\
\hline
\end{tabular}

\begin{tabular}{cc|c|c}
\hline & & $\begin{array}{c}\text { Measured } \\
\text { value }(\mathrm{MPa})\end{array}$ & $\begin{array}{c}\text { Theoretical } \\
\text { value }(\mathrm{MPa})\end{array}$ \\
\hline 4\# & segment stage & -3.881 & -2.11 \\
\hline $5 \#$ & segment stage & -5.867 & -4.02 \\
\hline $6 \#$ & segment stage & -6.283 & -4.47 \\
\hline $7 \#$ & segment stage & -7.529 & -5.65 \\
\hline $8 \#$ & segment stage & -8.344 & -5.66 \\
\hline 9\# & segment stage & -8.839 & -6.37 \\
\hline $10 \#$ & segment stage & -8.195 & -5.94 \\
\hline \multicolumn{2}{c|}{ side span closure } & -8.934 & -6.82 \\
\hline \multicolumn{2}{c|}{ middle span closure } & -9.128 & -7.16 \\
\hline \multicolumn{2}{c}{}
\end{tabular}

\section{Conclusion}

Due to the immature construction technology, it is necessary to monitor the construction of the new steel-concrete structure, PC composite box-girder with corrugated steel webs. In construction stages, Yingjie Bridge adopts adaptive control method for monitoring, and takes the stress and elevation of the main girder as the main control indicators to monitor the whole construction process of main girder. The results show that the forced condition of Yingjie Bridge is safe and reasonable, and the actual bridge alignment agrees with the ideal alignment. Good construction monitoring and control can improve the quality of corrugated steel webs girder bridges, and it greatly contributes to the development of greater spans.

\section{References}

[1] J. He, Y. Liu, A. Chen and T. Yoda: Mechanical behavior and analysis of composite bridges with corrugated steel webs: state-of-the-art, Int. J. Steel Struct. 12 (3) (2012) 321-338.

[2] R.J. Jiang, K.F.T. Au and Y.F. Xiao: Prestressed concrete girder bridges with corrugated steel webs: review, J. Struct. Eng. 141 (2) (2015) 4014108.

[3] Y. Liang: Monitoring Technology of Bridge Construction: Construction Technology (s1), $338-340$.

[4] J. He, Y. Liu, X. Xu, and L. Li, in: Loading capacity evaluation of composite box girder with corrugated webs and steel tube slab, Struct. Eng. Mech. 50 (4) (2014) 501-524.

[5] X. K. Hu: Researchon Adaptive System for the Construction Control of Long-Span Bridges. Hefei University of Technology.2017.

[6] X. F. Shi, H. F. Xiang: Application of adaptive control in cable-stayed bridge construction control: Annual meeting of bridge and Structural Engineering Society of China Civil Engineering Society (1998)

[7] K. J. Astrom, B.Wittenmark: Adaptive Control. 2nd ed. Reading, MA: Addison-Wesley, 1995. 